\section{(A) OPEN ACCESS}

\title{
Comprehensive testing for, and diagnosis of, sexually transmissible infections among Australian gay and bisexual men: findings from repeated, cross-sectional behavioural surveillance, 2003-2012
}

\author{
Martin Holt, ${ }^{1}$ Peter Hull, ${ }^{1}$ Toby Lea, ${ }^{1}$ Rebecca Guy ${ }^{2}$ Chris Bourne, ${ }^{3,4}$ \\ Garrett Prestage, ${ }^{2,5}$ Iryna Zablotska, ${ }^{2}$ John de Wit, ${ }^{1,6}$ Limin Mao ${ }^{1}$
}

\begin{abstract}
${ }^{1}$ Centre for Social Research in Health, University of New South Wales, Sydney, Australia ${ }^{2}$ The Kirby Institute, University of New South Wales, Sydney, Australia

${ }^{3}$ Sydney Sexual Health Centre, Sydney Hospital, Sydney, Australia

${ }^{4}$ School of Public Health and Community Medicine,

University of New South Wales, Sydney, Australia

${ }^{5}$ Australian Research Centre in Sex, Health and Society, La Trobe University, Melbourne, Australia

${ }^{6}$ Social and Organizational Psychology, Utrecht University, Utrecht, The Netherlands
\end{abstract}

\section{Correspondence to}

Dr Martin Holt, Centre for Social Research in Health, University of New South Wales, NSW 2052, Australia; m.holt@unsw.edu.au

Received 23 July 2013 Revised 27 September 2013 Accepted 20 October 2013

Published Online First

14 November 2013

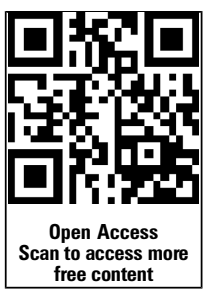

To cite: Holt M, Hull $P$, Lea T, et al. Sex Transm Infect 2014;90:208-215.

\section{ABSTRACT}

Objectives To analyse changes in testing for sexually transmissible infections (STI) among gay and bisexual men in Melbourne, Sydney and Queensland, Australia, particularly comprehensive STI testing (at least four tests from different anatomical sites in the previous year), and the characteristics of men who had such testing.

Method Data were analysed from repeated, crosssectional, community-based surveys conducted during 2003-2012. Trends in specific STI tests and comprehensive testing were assessed and the characteristics of participants who reported comprehensive STI testing were identified using multivariate logistic regression, stratified by HIV status.

Results Among HIV-negative and unknown status men ( $n=51$ 009), comprehensive STI and HIV testing increased substantially from $13 \%$ in 2003 to $34 \%$ in 2012. During the same period, comprehensive STI testing (excluding HIV testing) increased from $24 \%$ to $57 \%$ among HIV-positive men ( $n=5532)$. In both HIV status groups, comprehensive testing was more commonly reported by men who had unprotected anal intercourse with casual partners, and men with higher numbers of partners. Among HIV-negative/unknown status participants, comprehensive STI and HIV testing was also associated with education level, regional location and finding partners online. Among HIV-positive men, comprehensive STI testing was also associated with free time spent with gay men and illicit drug use. Comprehensive testing was related to a high annual rate of diagnosis with STIs (20\% of HIV-negative/unknown status men and $38 \%$ of HIV-positive men).

Conclusions There has been a substantial improvement in the proportion of gay and bisexual men in Melbourne, Sydney and Queensland who report comprehensive testing. Comprehensive testing is most likely among men whose practices put them at increased risk of infection, and is associated with a high rate of STI diagnosis. However, opportunities for comprehensive testing are still being missed, suggesting a need for its ongoing promotion.

\section{INTRODUCTION}

Over the last decade, there has been a concerted effort to increase the uptake of testing for HIV and other sexually transmissible infections (STI) among gay and bisexual men (GBM) in Australia. GBM are at increased risk of STIs, but opportunities for testing are often missed, increasing the likelihood of undiagnosed infections, onward transmission and disease sequelae. ${ }^{1-3}$

Current Australian guidelines recommend that all sexually active GBM should be tested at least annually for a range of STIs. ${ }^{4}$ The guidelines, first released in 2002 and revised three times, currently recommend that screening should include serology for HIV, syphilis and hepatitides A, B and C, an anal swab for gonorrhoea and chlamydia, a pharyngeal swab for gonorrhoea, and first-void urine for chlamydia, irrespective of sexual practice. The use of anal swabs is emphasised, given the high incidence of asymptomatic rectal STIs among GBM and their association with an increased likelihood of HIV infection. ${ }^{5}{ }^{6}$ The guidelines suggest more frequent testing for HIV-positive men (incorporated in their routine HIV monitoring), men who have unprotected anal intercourse or more than 10 partners in the previous 6 months, participate in group sex or use recreational drugs during sex. A recent review suggests that the Australian guidelines are unique because they specify a minimum testing frequency (annually) and more frequent testing for those at increased risk. ${ }^{7}$ The review found that European guidelines tend to be less specific (and less prescriptive), relying on clinical judgment to decide on the need for screening.

In addition to developing guidelines, a variety of other approaches has been used to promote comprehensive STI testing in Australia. ${ }^{8}$ Since 2003, STI testing campaigns, notably WhyTest in Sydney (20042007), Check-It-Out in Melbourne (2004-2006) and the national Drama Down Under campaign (2008date), have aimed to raise awareness of STIs and the need for regular testing. ${ }^{9-11}$ The campaign websites inform GBM about STI testing, provide access to short message service or email reminders, and enable the anonymous notification of sex partners following a diagnosis. ${ }^{9-11}$ Some clinics use prompts in patient information systems to remind clinicians to offer STI testing to GBM, while others have set up short message service (SMS) appointment reminders for patients. $^{8}{ }^{12}$ Evaluation showed the Check-It-Out campaign did not alter STI testing rates in Melbourne during 2004-2006. ${ }^{10}$ By contrast, the WhyTest and Drama Down Under campaigns achieved high levels of awareness, ${ }^{9} 11$ and significant increases were observed in the number of STI tests performed by clinics and the proportions of GBM reporting any STI testing. ${ }^{913}$ 
By 2007, around two-thirds of Australian GBM reported at least one STI test (other than HIV) in the previous year. ${ }^{13}{ }^{14}$ Anal and throat swabs were much less common than serology and urine tests. ${ }^{13}$ Repeated surveillance suggests that testing for a range of STIs has become more common, but there has been limited analysis of the completeness of this testing. ${ }^{15}$ Testing for HIV is more commonly reported by Australian gay men than testing for other STIs, with up to $70 \%$ of HIV-negative and untested men reporting a HIV test in the previous year. ${ }^{15-18}$ It appears that requests for HIV testing do not always prompt clinicians to suggest screening for other STIs (or vice versa). This disparity is partially explained by gay men continuing to view HIV as more important than other STIs. ${ }^{19}$ Studies consistently find that men who engage in practices that increase their risk of infection, such as having a high number of sexual partners or engaging in unprotected anal intercourse, are more likely to seek testing for HIV and STIs, and to test more frequently. ${ }^{2} 13$ 16-18 20

The aim of this analysis was to take stock of past achievements and identify future needs regarding the promotion of comprehensive STI and HIV testing to GBM. We examined changes in STI and HIV testing over the last 10 years to assess if improvements in comprehensive testing have continued or been sustained. In particular, we assessed the range of tests performed using specimens from different anatomical sites. Previous research has typically focused on men reporting any STI test, ${ }^{9} 10{ }^{13}$ but HIV and STI testing guidelines emphasise the need to concurrently test for multiple blood-borne viruses and STIs. ${ }^{4}$ We anticipated that comprehensive testing has become more common over time and would be associated with an increased rate of STI diagnosis. ${ }^{9} 13 \quad 1620$ We also expected that men who were more at risk of HIV and other STIs would be more likely to report comprehensive testing.

\section{METHODS}

\section{Participants and procedures}

Data were obtained through the Gay Community Periodic Surveys (GCPS); repeated, cross-sectional surveys in six Australian states and territories that recruit men at gay venues, events and clinics. ${ }^{14}$ Recruitment periods last for 2 weeks in each city and are timed to coincide with large, annual gay community events, such as Brisbane Pride, Midsumma in Melbourne and the Sydney Gay and Lesbian Mardi Gras. Eligible participants are adult men who regularly participate in the local gay community (ie, those who regularly attend local gay venues and events; temporary visitors are not eligible) and who have had sex with another man in the past 5 years. Participants are recruited by trained staff who ascertain whether men are eligible or not. Men who are eligible then opt to take part or not (the recruiters record the number who refuse). The response rate is typically $70 \%$. Consenting participants complete an anonymous questionnaire about relationships, sexual behaviour, HIV and STI testing, drug use and demographics. The study protocol is approved by the University of New South Wales Human Research Ethics Committee (ref HREC 09209).

For this analysis, we only included GCPS data from 2003 to 2012 collected annually in Melbourne, Sydney and Queensland (Brisbane, the Gold Coast and Cairns). The analysis was restricted to these locations because STI testing data have been collected more consistently and for longer there than in the other participating states and territories.

\section{Measures}

Our primary outcome measures (dependent variables) were related to HIV and STI testing in the 12 months prior to survey. The most recent HIV test among HIV-negative and unknown status men was assessed with the question 'When were you last tested for HIV antibodies?', with responses ranging from 'Less than a week ago' to 'Never tested'. For this analysis, we dichotomised these responses into 'HIV test in the last 12 months' vs 'No HIV test in last 12 months'. STI testing for all participants was assessed with the question 'Which of these sexual health tests have you had in the last 12 months?' The listed tests included anal swab, throat swab, urine sample, blood test for syphilis, and other blood test. Response options ranged from 'None' to ' 3 or more'. It should be noted that samples taken from different anatomical sites may be used to test for the same STI. ${ }^{4}$ The responses regarding blood test for syphilis and other blood test were combined into a new variable: any blood test other than HIV. Responses for anal swab, throat swab, urine sample and any blood test other than HIV were dichotomised (any test in last 12 months vs none). All men were classified as having undergone comprehensive STI testing if they reported an anal swab, throat swab, urine sample and any blood test other than HIV in the 12 months prior to survey. HIV-negative and unknown status participants were classified as having had comprehensive STI and HIV testing if in addition they reported having had a HIV test in the 12 months prior to survey. Scores on both comprehensive testing variables were dichotomised: 'comprehensive testing in last 12 months' vs 'no comprehensive testing'.

Independent variables included sociodemographic characteristics such as age, education level, employment status, residential location and sexual identity. Free time spent with gay men was included as a marker of involvement in gay social networks. Behavioural indicators that were assessed (for the 6 months prior to survey) included number of different male partners, any unprotected anal intercourse with casual male partners (UAIC) and any illicit drug use. We also assessed self-reported HIV status and self-reported diagnosis with any STI (other than HIV) in the 12 months prior to survey. For HIV-positive men, we included their HIV treatment status at the time of the survey and their last viral load test result. Details of these and other GCPS measures and indicators are available elsewhere. ${ }^{14}$

\section{Data analysis}

Analyses were conducted separately for HIV-negative and unknown status men and HIV-positive men. $\chi^{2}$ tests for linear trends were conducted to examine changes in the proportions of participants who reported individual tests, any test and comprehensive testing over the time period 2003-2012. We also analysed trends in comprehensive testing among men who had engaged in any UAIC, and those who had more than 10 male sex partners in the 6 months prior to survey. For HIV-negative and unknown status men, trends in comprehensive testing with and without HIV testing are reported. Sociodemographic characteristics were examined to determine if there were any major changes to the sample composition over time. Because the main sample characteristics (eg, age, recruitment location) were reasonably stable, we did not control for these in trend analyses. Controlling for year of data collection, we used logistic regression to identify the likelihood of comprehensive testing by different HIV status groups, by men who did and did not report UAIC, and by men who had more than 10 vs 10 or fewer male partners. Bivariate analyses ( $\chi^{2}$ tests and tests) were used to identify variables associated with comprehensive testing in 2012. Variables found to be associated at a significance level of $\mathrm{p}<0.05$ were entered into a multivariate logistic regression analysis to assess independent associations with comprehensive STI testing in 2012. All analyses were conducted with SPSS (V.20). 
Table 1 Trends in testing for sexually transmissible infections in the 12 months prior to survey, 2003-2012, by HIV status

\begin{tabular}{|c|c|c|c|c|c|c|c|c|c|c|c|}
\hline & \multicolumn{10}{|l|}{ Year } & \multirow[b]{2}{*}{$\begin{array}{l}\chi^{2} \text { test for trend } \\
(p)\end{array}$} \\
\hline & $\begin{array}{l}2003 \\
\mathrm{n}(\%)\end{array}$ & $\begin{array}{l}2004 \\
\mathrm{n}(\%)\end{array}$ & $\begin{array}{l}2005 \\
\mathrm{n}(\%)\end{array}$ & $\begin{array}{l}2006 \\
\text { n (\%) }\end{array}$ & $\begin{array}{l}2007 \\
\text { n (\%) }\end{array}$ & $\begin{array}{l}2008 \\
\mathrm{n}(\%)\end{array}$ & $\begin{array}{l}2009 \\
\mathrm{n}(\%)\end{array}$ & $\begin{array}{l}2010 \\
\mathrm{n}(\%)\end{array}$ & $\begin{array}{l}2011 \\
\text { n (\%) }\end{array}$ & $\begin{array}{l}2012 \\
\text { n (\%) }\end{array}$ & \\
\hline \multicolumn{12}{|c|}{ HIV-negative and untested/unknown status men } \\
\hline Anal swab & $954(20.1)$ & $1149(23.8)$ & $1341(29.5)$ & $1755(35.2)$ & $1775(35.2)$ & $1813(38.0)$ & $1826(37.4)$ & $2324(39.2)$ & $2343(40.5)$ & $2163(40.5)$ & $880.2(<0.001)$ \\
\hline Blood test other than for HIV & $2435(51.3)$ & $2519(52.1)$ & 2361 (51.9) & $2672(51.9)$ & $2578(51.2)$ & $2503(52.5)$ & $2791(57.2)$ & $3738(63.1)$ & $3579(61.8)$ & $3352(62.8)$ & $397.2(<0.001)$ \\
\hline Throat swab & $1293(27.2)$ & $1499(31.0)$ & $1629(35.8)$ & $2023(39.3)$ & $2031(40.3)$ & $1998(41.9)$ & $2010(41.2)$ & $2549(43.0)$ & $2537(43.8)$ & $2351(44.1)$ & $511.6(<0.001)$ \\
\hline Urine sample & $1756(37.0)$ & $2040(42.2)$ & $2065(45.4)$ & $2434(47.3)$ & $2405(47.7)$ & $2432(51.0)$ & $2400(49.2)$ & $3109(52.5)$ & $3050(52.7)$ & $2836(53.1)$ & $422.8(<0.001)$ \\
\hline HIV test & $2768(58.5)$ & $2936(60.9)$ & $2812(62.1)$ & $3264(63.9)$ & $3215(64.6)$ & 3052 (64.6) & $3041(63.5)$ & 3596 (61.7) & $3716(65.2)$ & $3366(63.8)$ & $19.3(<0.001)$ \\
\hline Any test (including HIV tests) & $3402(71.7)$ & $3535(73.1)$ & $3308(72.8)$ & $3736(72.6)$ & $3656(72.6)$ & 3474 (72.9) & $3490(71.6)$ & $4276(72.2)$ & $4305(74.3)$ & $3889(72.9)$ & $1.7(0.20)$ \\
\hline Comprehensive STI testing* & 646 (13.6) & $812(16.8)$ & $992(21.8)$ & $1316(25.6)$ & $1326(26.3)$ & $1374(28.8)$ & 1539 (31.6) & $2093(35.3)$ & $2102(36.3)$ & $1963(36.8)$ & $1445.9(<0.001)$ \\
\hline Comprehensive STI and HIV testing $\dagger$ & $604(12.7)$ & $763(15.8)$ & $940(20.7)$ & $1223(23.8)$ & $1262(25.0)$ & $1273(26.7)$ & $1434(29.4)$ & $1931(32.6)$ & 1955 (33.8) & $1835(34.4)$ & $1280.8(<0.001)$ \\
\hline Total & $4746(100)$ & $4837(100)$ & $4545(100)$ & $5146(100)$ & $5038(100)$ & $4768(100)$ & $4877(100)$ & $5923(100)$ & $5792(100)$ & $5337(100)$ & \\
\hline \multicolumn{12}{|l|}{ HIV-positive men } \\
\hline Anal swab & $186(35.8)$ & $206(37.9)$ & $212(44.6)$ & $267(46.9)$ & $281(52.1)$ & $288(53.1)$ & $300(59.3)$ & $379(60.3)$ & $410(64.2)$ & $356(62.7)$ & $199.0(<0.001)$ \\
\hline Blood test other than for HIV & $387(74.4)$ & $405(74.3)$ & $353(74.3)$ & $425(74.7)$ & $407(75.5)$ & $410(75.6)$ & $437(86.4)$ & $549(87.3)$ & $567(88.7)$ & $493(86.8)$ & $106.4(<0.001)$ \\
\hline Throat swab & $212(40.8)$ & $247(45.3)$ & $252(53.1)$ & $303(53.3)$ & $289(53.6)$ & $308(56.8)$ & $318(62.8)$ & $381(60.6)$ & $417(65.3)$ & $373(65.7)$ & $128.1(<0.001)$ \\
\hline Urine sample & $244(46.9)$ & $270(49.5)$ & $256(53.9)$ & $321(56.4)$ & $322(59.7)$ & $340(62.7)$ & $337(66.6)$ & $442(70.3)$ & $480(75.1)$ & $417(73.4)$ & $205.3(<0.001)$ \\
\hline Any STI test & $484(93.1)$ & $513(94.1)$ & $445(93.7)$ & $543(95.4)$ & $505(93.7)$ & $509(93.9)$ & $488(96.4)$ & $603(95.9)$ & $606(94.8)$ & $546(96.1)$ & $6.93(0.008)$ \\
\hline Comprehensive STI testing* & $126(24.2)$ & $163(29.9)$ & $159(33.5)$ & $209(36.7)$ & $218(40.4)$ & $236(43.5)$ & $255(50.4)$ & $336(53.4)$ & $375(58.7)$ & $325(57.2)$ & $284.9(<0.001)$ \\
\hline Total & $520(100)$ & $544(100)$ & $475(100)$ & $569(100)$ & $539(100)$ & $542(100)$ & $506(100)$ & $629(100)$ & $639(100)$ & $568(100)$ & \\
\hline
\end{tabular}

*At least four different STI tests in the 12 months prior to survey, not including HIV testing.

tAt least five different STI tests in the 12 months prior to survey, including HIV testing.

STI, sexually transmissible infection. 


\section{RESULTS}

\section{Participant characteristics}

Overall, 56541 men completed surveys in the period 20032012. Of these men, $79.5 \%$ reported that they were HIV-negative, $10.7 \%$ were untested for HIV or of unknown HIV status, and 9.8\% were HIV-positive. Forty-two per cent of respondents were recruited in Sydney, 34.8\% in Melbourne and $23.7 \%$ in Queensland. The majority of participants $(84.9 \%)$ resided in a city/metropolitan area. The mean age of respondents was 35.7 years $(\mathrm{SD}=11.26)$ with a median of 35 (range 18-91). The majority of respondents was in paid employment (79.4\%), had a university degree (50.3\%), and identified as gay/ homosexual (89.0\%). Minorities of respondents identified as bisexual $(6.7 \%)$ or heterosexual $(1.8 \%)$ or reported an Aboriginal or Torres Strait Islander background (3.5\%).

\section{Changes in rates of STI testing from 2003 to 2012}

Analyses of rates of testing for STIs from 2003 to 2012 show substantial upward trends for all types of STI tests and for comprehensive testing (see table 1). The most notable increases were in the use of anal and throat swabs. While the proportion of HIV-negative and unknown status participants reporting any STI test (including HIV tests) remained relatively stable at over $70 \%$, the proportion reporting comprehensive STI and HIV testing increased markedly from $12.7 \%$ in 2003 to $34.4 \%$ in 2012. HIV-positive men were considerably more likely than HIV-negative and untested men to report STI testing, with the proportion of HIV-positive men reporting any STI test at over 90\% during 2003-2012. Comprehensive STI testing became much more likely among HIV-positive men, increasing from $24.2 \%$ in 2003 to $58.7 \%$ in 2012 . Controlling for the year of data collection, HIV-positive men were substantially more likely than HIV-negative and unknown status men to report comprehensive STI testing, excluding HIV testing (adjusted $\mathrm{OR}=2.05$, $95 \%$ CI 1.94 to $2.17, \mathrm{p}<0.001$ ).

In every year (and in both HIV status groups), comprehensive testing was more common among men who had UAIC and men who had more than 10 male partners in the 6 months prior to survey (see table 2). Controlling for year of data collection, comprehensive testing (including HIV testing) was more likely to be reported by HIV-negative and unknown status men who had UAIC versus those who did not $(\mathrm{AOR}=1.88,95 \%$ CI 1.79 to $1.97, \mathrm{p}<0.001)$ and by HIV-negative and unknown status men who had more than 10 male partners versus those with fewer partners $(\mathrm{AOR}=2.42,95 \%$ CI 2.31 to $2.53, \mathrm{p}<0.001)$. Among HIV-positive men, comprehensive STI testing (not including HIV testing) was more likely among men who had UAIC versus those who did not $(\mathrm{AOR}=2.57,95 \%$ CI 2.30 to $2.88, \mathrm{p}<0.001)$, and those who had more than 10 versus fewer partners $(\mathrm{AOR}=2.41,95 \%$ CI 2.15 to $2.71, \mathrm{p}<0.001)$.

\section{Factors associated with comprehensive testing in $\mathbf{2 0 1 2}$}

A range of factors was associated with an increased likelihood of comprehensive STI and HIV testing by HIV-negative and untested/unknown status men (see table 3), including living in a metropolitan area, identifying as gay, having a higher number of male partners, engaging in protected or unprotected anal intercourse with casual partners and finding male partners online. Among HIV-positive men, comprehensive STI testing was associated with spending more free time with gay men, having more than 10 male partners in the last 6 months, finding partners online and illicit drug use (see table 4). Comprehensive testing was not associated with HIV-positive men's current HIV 
Table 3 Factors associated with comprehensive STI and HIV testing by HIV-negative and untested/unknown status men in 2012

\begin{tabular}{|c|c|c|c|c|c|c|}
\hline & $\begin{array}{l}\text { No comprehensive } \\
\text { testing }(\mathrm{n}=3502) \\
\mathrm{n}(\%)\end{array}$ & $\begin{array}{l}\text { Comprehensive } \\
\text { testing* }(\mathrm{n}=1835) \\
\mathrm{n}(\%)\end{array}$ & $\begin{array}{l}\text { Unadjusted } \\
\text { OR }(95 \% \mathrm{Cl})\end{array}$ & $\mathrm{p}$ Value & $\begin{array}{l}\text { Adjusted } \\
\text { OR }(95 \% \mathrm{Cl})\end{array}$ & p Value \\
\hline Age in years $(M, S D)$ & $37.3(12.5)$ & $34.9(10.5)$ & 0.98 (0.98 to 0.99$)$ & $<0.001$ & 0.98 (0.98 to 0.99$)$ & $<0.001$ \\
\hline \multicolumn{7}{|l|}{ Free time spent with gay men } \\
\hline None/some & $2227(63.6)$ & $1009(55.0)$ & 1.00 & & 1.00 & \\
\hline A lot & $1275(36.4)$ & $826(45.0)$ & $1.43(1.27$ to 1.60$)$ & $<0.001$ & 1.27 (1.12 to 1.44$)$ & $<0.001$ \\
\hline \multicolumn{7}{|l|}{ Education } \\
\hline Has not attended university & $1686(48.1)$ & 799 (43.5) & 1.00 & & 1.00 & \\
\hline University degree & $1816(51.9)$ & $1036(56.5)$ & 1.20 (1.08 to 1.35$)$ & 0.001 & 1.19 (1.05 to 1.35$)$ & 0.008 \\
\hline \multicolumn{7}{|l|}{ Employment } \\
\hline Not in paid employment & $672(19.2)$ & $295(16.1)$ & 1.00 & & 1.00 & \\
\hline Any paid employment & $2830(80.8)$ & $1540(83.9)$ & 1.24 (1.07 to 1.44$)$ & 0.005 & 1.12 (0.95 to 1.32$)$ & 0.19 \\
\hline \multicolumn{7}{|l|}{ Residential location } \\
\hline Regional area & $516(14.7)$ & $184(10.0)$ & 1.00 & & 1.00 & \\
\hline City/metropolitan area & $2986(85.3)$ & $1651(90.0)$ & 1.55 (1.30 to 1.85$)$ & $<0.001$ & 1.49 (1.23 to 1.82$)$ & $<0.001$ \\
\hline \multicolumn{7}{|l|}{ Sexual identity } \\
\hline Bisexual/heterosexual/other & 479 (13.7) & $142(7.7)$ & 1.00 & & 1.00 & \\
\hline Gay/homosexual & $3023(86.3)$ & $1693(92.3)$ & 1.89 (1.55 to 2.30$)$ & $<0.001$ & 1.57 (1.26 to 1.95$)$ & $<0.001$ \\
\hline \multicolumn{7}{|l|}{ Number of male sex partners in last 6 months } \\
\hline None & $637(18.3)$ & $77(4.2)$ & 1.00 & & 1.00 & \\
\hline $1-10$ & 2305 (66.4) & $1130(62.0)$ & 4.06 (3.17 to 5.19$)$ & $<0.001$ & 2.01 (1.52 to 2.64$)$ & $<0.001$ \\
\hline More than 10 & $531(15.3)$ & $617(33.8)$ & 9.61 (7.39 to 12.51$)$ & $<0.001$ & $2.92(2.13$ to 4.01$)$ & $<0.001$ \\
\hline \multicolumn{7}{|l|}{ Sex with casual male partners in last 6 months } \\
\hline No casual partners & $1642(46.9)$ & $384(20.9)$ & 1.00 & & 1.00 & \\
\hline Casual sex but no anal intercourse & $497(14.2)$ & $194(10.6)$ & 1.67 (1.37 to 2.04$)$ & $<0.001$ & 1.15 (0.92 to 1.44$)$ & 0.23 \\
\hline Condoms always used for anal intercourse & $877(25.0)$ & $749(40.8)$ & 3.65 (3.15 to 4.23$)$ & $<0.001$ & 2.10 (1.75 to 2.53$)$ & $<0.001$ \\
\hline Any unprotected anal intercourse & $486(13.9)$ & $508(27.7)$ & 4.47 (3.78 to 5.28$)$ & $<0.001$ & 2.14 (1.74 to 2.64$)$ & $<0.001$ \\
\hline \multicolumn{7}{|c|}{ Found male sex partners on internet in last 6 months } \\
\hline No & $2483(70.9)$ & $865(47.1)$ & 1.00 & & 1.00 & \\
\hline Yes & $1019(29.1)$ & $970(52.9)$ & 2.73 (2.43 to 3.07 ) & $<0.001$ & $1.44(1.25$ to 1.66$)$ & $<0.001$ \\
\hline \multicolumn{7}{|c|}{ Diagnosed with any STI (other than HIV) in last 12 months } \\
\hline No & $3303(94.3)$ & $1464(79.8)$ & 1.00 & & 1.00 & \\
\hline Yes & $199(5.7)$ & $371(20.2)$ & 4.21 (3.50 to 5.05$)$ & $<0.001$ & 3.01 (2.46 to 3.68$)$ & $<0.001$ \\
\hline \multicolumn{7}{|l|}{ Any illicit drug use in last 6 months } \\
\hline No & $1282(36.6)$ & $447(24.4)$ & 1.00 & & 1.00 & \\
\hline Yes & $2220(63.4)$ & $1388(75.6)$ & 1.79 (1.58 to 2.04$)$ & $<0.001$ & 1.36 (1.18 to 1.56$)$ & $<0.001$ \\
\hline \multicolumn{7}{|l|}{ Recruitment venue } \\
\hline Gay community events & 1807 (51.6) & $847(46.2)$ & 1.00 & & 1.00 & \\
\hline Sexual health clinics & 127 (3.6) & $100(5.4)$ & 1.68 (1.28 to 2.21$)$ & $<0.001$ & 1.96 (1.43 to 2.68$)$ & $<0.001$ \\
\hline Social venues (eg, bars) & 1135 (32.4) & $645(35.1)$ & 1.21 (1.07 to 1.38 ) & 0.003 & 1.05 (0.92 to 1.21$)$ & 0.47 \\
\hline Sex-on-premises venues & $433(12.4)$ & $243(13.2)$ & $1.20(1.00$ to 1.43$)$ & 0.05 & $1.00(0.82$ to 1.23$)$ & 0.97 \\
\hline
\end{tabular}

${ }^{*}$ Comprehensive testing is defined as at least five different STI tests in the 12 months prior to survey, including HIV testing.

STI, sexually transmissible infection.

treatment status. Men who reported comprehensive testing in 2012 were substantially more likely to report a diagnosis with an STI other than HIV (20.2\% vs 5.7\% among HIV-negative and untested men; $37.8 \%$ vs $7.4 \%$ among HIV-positive men).

\section{DISCUSSION}

Our investigation of trends in STI testing from repeated, behavioural surveillance of GBM in Melbourne, Sydney and Queensland found that comprehensive testing has become substantially more common. Between 2003 and 2012, there was a nearly threefold increase in comprehensive STI and HIV testing among HIV-negative and unknown status men, and a doubling of comprehensive STI testing among HIV-positive men. Urine samples, HIV tests and other blood tests, as well as pharyngeal and anal swabs, have all become considerably more likely to be reported. Comprehensive testing remains more common among men whose practices put them at increased risk of infection, notably men who report UAIC and men with higher numbers of sexual partners. HIV-positive men are more likely to report comprehensive testing for STIs than HIV-negative and untested/ unknown status men. This is presumably a result of sexual health screening being incorporated into routine HIV monitoring. ${ }^{4}$ These findings are consistent with previous research about which GBM are most likely to present for testing. ${ }^{2} \quad 13 \quad 16-1820$ The high rates of STI diagnoses among men reporting comprehensive testing lend weight to the recommendation that all sexually active GBM should be screened for a range of STIs each year, irrespective of sexual practice. ${ }^{4}$

Despite substantial improvements, the proportion of men reporting comprehensive testing continues to lag well behind 
Table 4 Factors associated with comprehensive STI testing by HIV-positive men in 2012

\begin{tabular}{|c|c|c|c|c|c|c|}
\hline & $\begin{array}{l}\text { No comprehensive } \\
\text { testing }(n=243) \\
n(\%)\end{array}$ & $\begin{array}{l}\text { Comprehensive } \\
\text { testing* }(n=325) \\
n(\%)\end{array}$ & $\begin{array}{l}\text { Unadjusted } \\
\text { OR (95\% Cl) }\end{array}$ & $\mathrm{p}$ Value & $\begin{array}{l}\text { Adjusted } \\
\text { OR (95\% Cl) }\end{array}$ & p Value \\
\hline Age in years $(M, S D)$ & $46.6(10.5)$ & $42.7(10.0)$ & $0.96(0.95$ to 0.98$)$ & $<0.001$ & $0.98(0.96$ to 1.00$)$ & 0.048 \\
\hline \multicolumn{7}{|l|}{ Free time spent with gay men } \\
\hline None/some & $149(61.3)$ & $149(45.8)$ & 1.00 & & 1.00 & \\
\hline A lot & $94(38.7)$ & $176(54.2)$ & 1.87 (1.34 to 2.63$)$ & $<0.001$ & 1.51 (1.01 to 2.27 ) & 0.04 \\
\hline \multicolumn{7}{|l|}{ Education } \\
\hline Has not attended university & $143(58.8)$ & $183(56.3)$ & 1.00 & & & \\
\hline University degree & $100(41.2)$ & $142(43.7)$ & 1.11 (0.79 to 1.55$)$ & 0.54 & & \\
\hline \multicolumn{7}{|l|}{ Employment } \\
\hline Not in paid employment & $80(32.9)$ & $86(26.5)$ & 1.00 & & & \\
\hline Any paid employment & $163(67.1)$ & $239(73.5)$ & $1.36(0.95$ to 1.96$)$ & 0.09 & & \\
\hline \multicolumn{7}{|l|}{ Residential location } \\
\hline Regional area & $18(7.4)$ & $40(12.3)$ & 1.00 & & & \\
\hline City/metropolitan area & $225(92.6)$ & $285(87.7)$ & 0.57 (0.32 to 1.02$)$ & 0.06 & & \\
\hline \multicolumn{7}{|l|}{ Sexual identity } \\
\hline Bisexual/heterosexual/other & $12(4.9)$ & $19(5.8)$ & 1.00 & & & \\
\hline Gay/homosexual & $231(95.1)$ & $306(94.2)$ & 0.84 (0.40 to 1.76$)$ & 0.64 & & \\
\hline \multicolumn{7}{|l|}{ Number of male sex partners in last 6 months } \\
\hline None & $61(25.4)$ & $17(5.3)$ & 1.00 & & 1.00 & \\
\hline $1-10$ & $126(52.5)$ & $144(44.6)$ & $4.10(2.23$ to 7.39$)$ & $<0.001$ & $1.76(0.79$ to 3.93$)$ & 0.17 \\
\hline More than 10 & $53(22.1)$ & $162(50.2)$ & 10.97 (5.90 to 20.40) & $<0.001$ & 2.66 (1.05 to 6.72$)$ & 0.04 \\
\hline \multicolumn{7}{|l|}{ Sex with casual male partners in last 6 months } \\
\hline No casual partners & $104(42.8)$ & $44(13.5)$ & 1.00 & & 1.00 & \\
\hline Casual sex but no anal intercourse & $26(10.7)$ & $17(5.2)$ & 1.55 (0.76 to 3.13$)$ & 0.23 & 0.85 (0.36 to 2.04$)$ & 0.72 \\
\hline Condoms always used for anal intercourse & $34(14.0)$ & $55(16.9)$ & $3.82(2.20$ to 6.65$)$ & $<0.001$ & 1.84 (0.88 to 3.84$)$ & 0.11 \\
\hline Any unprotected anal intercourse & $79(32.5)$ & $209(64.3)$ & 6.25 (4.04 to 9.68$)$ & $<0.001$ & $1.90(0.95$ to 3.80$)$ & 0.07 \\
\hline \multicolumn{7}{|c|}{ Found male sex partners on internet in last 6 months } \\
\hline No & $164(67.5)$ & $116(35.7)$ & 1.00 & & 1.00 & \\
\hline Yes & $79(32.5)$ & $209(64.3)$ & 3.74 (2.63 to 5.32$)$ & $<0.001$ & 1.42 (0.89 to 2.25$)$ & 0.14 \\
\hline \multicolumn{7}{|c|}{ Diagnosed with any STI (other than HIV) in last 12 months } \\
\hline No & $225(92.6)$ & $202(62.2)$ & 1.00 & & 1.00 & \\
\hline Yes & $18(7.4)$ & $123(37.8)$ & $7.61(4.48$ to 12.93$)$ & $<0.001$ & $4.56(2.54$ to 8.20$)$ & $<0.001$ \\
\hline \multicolumn{7}{|c|}{ On antiretroviral treatment for HIV at the time of the survey } \\
\hline No & $45(18.5)$ & $74(22.8)$ & 1.00 & & & \\
\hline Yes & $198(81.5)$ & $251(77.2)$ & 0.77 (0.51 to 1.17$)$ & 0.22 & & \\
\hline \multicolumn{7}{|l|}{ Last HIV viral load test result } \\
\hline Detectable/don't know & $47(19.3)$ & 74 (22.8) & 1.00 & & & \\
\hline Undetectable & $196(80.7)$ & $251(77.2)$ & 0.81 (0.54 to 1.23 ) & 0.32 & & \\
\hline \multicolumn{7}{|l|}{ Any illicit drug use in last 6 months } \\
\hline No & $74(30.5)$ & $36(11.1)$ & 1.00 & & 1.00 & \\
\hline Yes & $169(69.5)$ & $289(88.9)$ & $3.52(2.26$ to 5.46$)$ & $<0.001$ & 1.77 (1.06 to 2.93$)$ & 0.03 \\
\hline \multicolumn{7}{|l|}{ Recruitment venue } \\
\hline Gay community events & $100(41.2)$ & $146(44.9)$ & 1.00 & & 1.00 & \\
\hline Sexual health clinics & $63(25.9)$ & 49 (15.1) & 0.53 (0.34 to 0.84$)$ & 0.006 & 0.64 (0.37 to 1.10$)$ & 0.11 \\
\hline Social venues (eg, bars) & $55(22.6)$ & $83(25.5)$ & 1.03 (0.68 to 1.58$)$ & 0.88 & 0.78 (0.47 to 1.28$)$ & 0.32 \\
\hline Sex-on-premises venues & $25(10.3)$ & $47(14.5)$ & $1.29(0.74$ to 2.23$)$ & 0.37 & 1.06 (0.56 to 2.01$)$ & 0.86 \\
\hline
\end{tabular}

${ }^{*}$ Comprehensive testing is defined as at least four different STI tests in the 12 months prior to survey, not including HIV testing.

STI, sexually transmissible infection.

those who have had any STI or HIV test in the previous year, illustrating that opportunities to perform comprehensive testing continue to be missed. Our findings echo previous research that found that anal and throat swabs are less likely to be reported by GBM compared with other types of specimen collection, ${ }^{13}$ suggesting a continuing lack of adherence to testing guidelines. ${ }^{4}$ This underlines the importance of the ongoing promotion of testing guidelines to GBM and their doctors. The observed higher rates of STI diagnosis among GBM who undergo comprehensive testing, regardless of their sexual practices, underline the importance of promoting a full STI screen for GBM at least once a year, irrespective of sexual practice. In Australia, this recommendation needs to be particularly promoted to general practitioners because they undertake the bulk of HIV/STI testing. ${ }^{12}$ In terms of the development of international STI testing guidelines, our results suggest that 'risk profiling' may be useful in identifying GBM who would benefit from more frequent screening, but a focus on specific sexual 
practices should not impede the promotion of a minimum screening frequency for sexually active GBM, such as once or twice a year. $^{7}$

Some limitations of our study should be borne in mind. The GCPS specifically target sexually active GBM in metropolitan areas of Australia. ${ }^{14}$ The sample is, therefore, not representative of all GBM in Australia, who may be younger, less educated and have fewer recent sexual partners. ${ }^{14} 2122$ Our sample does, however, provide a good representation of men at high risk for HIV and other STIs. ${ }^{1414}$ Because of the repeated, cross-sectional design it is not possible to identify changes in patterns of testing over time among the same individuals or groups of men, nor can we identify specific drivers of comprehensive testing or STI diagnoses. It should also be noted that our definition of comprehensive STI testing does not capture whether men had a range of STI tests on the same or different occasions (given the recall period was the 12 months prior to survey). Lastly, the reliance on selfreport data means that the levels of STI testing presented here may be inflated by social desirability and recall biases. ${ }^{2}$

Despite these limitations, our analysis demonstrates that comprehensive STI testing has become more common over time among GBM in the three most populous states in Australia, and is more common among men for whom more frequent testing is recommended. We consider this to be at least partially the result of concerted efforts to promote comprehensive testing in educational campaigns, the development of testing guidelines and the use of automated reminders for patients and doctors. ${ }^{4}$ 9-12 However, our findings also show that a substantial proportion of GBM in Melbourne, Sydney and Queensland do not benefit from comprehensive STI testing, because they do not present for testing, are not offered testing, or receive some but not all of the recommended tests. Identifying why doctors only offer a limited range of tests when GBM request testing, for example, would merit further research.

Our findings suggest that efforts to publicise and encourage comprehensive STI and HIV testing among GBM in Melbourne, Sydney and Queensland have been partially successful. We encourage the development and implementation of effective strategies to increase the uptake and comprehensiveness of testing, particularly the promotion of regular comprehensive testing for all sexually active GBM, regardless of sexual practice.

Key messages

- Since 2003, substantially more gay and bisexual men in Melbourne, Sydney and Queensland report comprehensive sexually transmissible infections (STI) testing (at least four tests from different anatomical sites in the previous year).

- Comprehensive testing is most likely among men who engage in practices that put them at increased risk of STIs, and is associated with a substantially higher rate of STI diagnosis.

- Despite improvements over time, opportunities for comprehensive testing are still being missed, suggesting a need for the ongoing promotion of comprehensive testing.

Correction notice This article has been corrected since it was published Online First. In table 2, the two subgroups 'No anal intercourse with casual male partners' have been amended to 'No unprotected anal intercourse with casual male partners'.

Handling editor Jackie A Cassell
Acknowledgements The authors thank all the participants in the Gay Community Periodic Surveys and the state and territory AIDS Councils that undertook recruitment.

Contributors MH, PH, TL, GP, IZ, JdW and LM contribute to the design of the Gay Community Periodic Surveys, including questionnaire construction, data collection, analysis and reporting. Following discussions with $\mathrm{CB}$ and $\mathrm{RG}, \mathrm{MH}$ had the idea for the analysis presented here and took primary responsibility for writing and revising the paper; he is the guarantor. PH and TL undertook the statistical analysis, with input from $\mathrm{MH}, \mathrm{LM}$ and JdW, and drafted the methods and results sections. All authors commented on drafts of the paper and agreed with the final version.

Funding The Centre for Social Research in Health and The Kirby Institute receive funding from the Australian Government Department of Health and Ageing. The Gay Community Periodic Surveys are funded by the health departments from each participating state and territory.

\section{Competing interests None.}

Ethics approval University of New South Wales Human Research Ethics Committee.

Provenance and peer review Not commissioned; externally peer reviewed.

Data sharing statement Requests to use the Gay Community Periodic Survey dataset will be considered by the chief investigators on a case-by-case basis. Requests should be made to the first author.

Open Access This is an Open Access article distributed in accordance with the Creative Commons Attribution Non Commercial (CC BY-NC 3.0) license, which permits others to distribute, remix, adapt, build upon this work non-commercially, and license their derivative works on different terms, provided the original work is properly cited and the use is non-commercial. See: http://creativecommons.org/ licenses/by-nc/3.0/

\section{REFERENCES}

1 Grulich A, De Visser RO, Smith AMA, et al. Sexually transmissible infection and blood-borne virus history in a representative sample of adults. Aust N Z J Public Health 2003:27:234-41.

2 Guy R, Goller JL, Spelman T, et al. Does the frequency of HIV and STI testing among MSM in primary care adhere with Australian guidelines? Sex Transm Infect 2010;86:371-6

3 Gray RT, Hoare A, Prestage GP, et al. Frequent testing of highly sexually active gay men is required to control syphilis. Sex Transm Dis 2010;37:298-305.

4 STIGMA. Sexually transmitted infection testing guidelines for men who have sex with men 2010. Sydney: Sexually Transmissible Infections in Gay Men Action Group, 2010.

5 Jin FY, Prestage GP, Imrie J, et al. Anal sexually transmitted infections and risk of HIV infection in homosexual men. J Acquir Immune Defic Syndr 2010;53: $144-9$

6 Kent CK, Chaw JK, Wong W, et al. Prevalence of rectal, urethral, and pharyngeal chlamydia and gonorrhea detected in 2 clinical settings among men who have sex with men: San Francisco, California, 2003. Clin Infect Dis 2005;41:67-74.

7 Patel RR, Patel S, Clarke E, et al. Guidance and practice on frequency of HIV and sexually transmitted infection testing in men who have sex with men-What is the European situation? Int J STD AIDS 2013; in press (doi:10.1177/ 095646241349770)

8 Zou H, Fairley CK, Guy R, et al. The efficacy of clinic-based interventions aimed at increasing screening for bacterial sexually transmitted infections among men who have sex with men: a systematic review. Sex Transm Dis 2012;39:382-7.

9 Pedrana A, Hellard M, Guy R, et al. Stop the Drama Downunder: a social marketing campaign increases HIV/sexually transmitted infection knowledge and testing in Australian gay men. Sex Transm Dis 2012:39:651-8.

10 Guy R, Goller J, Leslie D, et al. No increase in HIV or sexually transmissible infection testing following a social marketing campaign among men who have sex with men. J Epidemiol Community Health 2009;63:391-6.

11 Bourne C, Zablotska I, Williamson A, et al. Promotion and uptake of a new online partner notification and retesting reminder service for gay men. Sex Health 2012;9:360-7.

12 Bourne C, Knight V, Guy R, et al. Short message service reminder intervention doubles sexually transmitted infection/HIV re-testing rates among men who have sex with men. Sex Transm Infect 2011:87:229-31.

13 Zablotska I, Imrie J, Bourne C, et al. Improvements in sexual health testing among gay men in Sydney, Australia, 2003-2007. Int J STD AIDS 2008;19:758-60

14 Zablotska I, Kippax S, Grulich A, et al. Behavioural surveillance among gay men in Australia: methods, findings and policy implications for the prevention of HIV and other sexually transmissible infections. Sex Health 2011;8:272-9.

15 De Wit J, Holt M, Treloar C. eds. HIVIAIDS, hepatitis and sexually transmissible infections in Australia: annual report of trends in behaviour 2012. Sydney: National Centre in HIV Social Research, The University of New South Wales, 2012. 
16 Holt M, Rawstorne P, Wilkinson J, et al. HIV testing, gay community involvement and internet use: social and behavioural correlates of HIV testing among Australian men who have sex with men. AIDS Behav 2012:16:13-22.

17 Jin FY, Prestage G, Law MG, et al. Predictors of recent HIV testing in homosexual men in Australia. HIV Med 2002;3:271-6.

18 Zablotska I, Holt M, De Wit J, et al. Gay men who are not getting tested for HIV. AIDS Behav 2012;16:1887-94.

19 Holt M, Bernard D, Race K. Gay men's perceptions of sexually transmissible infections and their experiences of diagnosis: 'part of the way of life' to feeling 'dirty and ashamed'. Sex Health 2010;7:411-16.
20 Prestage GP, Hudson J, Jin F, et al. Testing for HIV and sexually transmissible infections within a mainly online sample of gay men who engage in group sex. Sex Transm Infect 2009:85:70-4.

21 Smith AMA, Rissel CE, Richters J, et al. Sex in Australia: sexual identity, sexual attraction and sexual experience among a representative sample of adults. Aust $N Z$ J Public Health 2003;27:138-45.

22 Grulich AE, de Visser RO, Smith AMA, et al. Sex in Australia: homosexual experience and recent homosexual encounters. Aust N Z J Public Health 2003;27: $155-63$ 